\title{
Berkeleydione and Berkeleytrione, New Bioactive Metabolites from an Acid Mine Organism
}

Donald B. Stierle, Andrea A. Stierle, J. David Hobbs, and Jon Clardy

\section{Supporting Information}




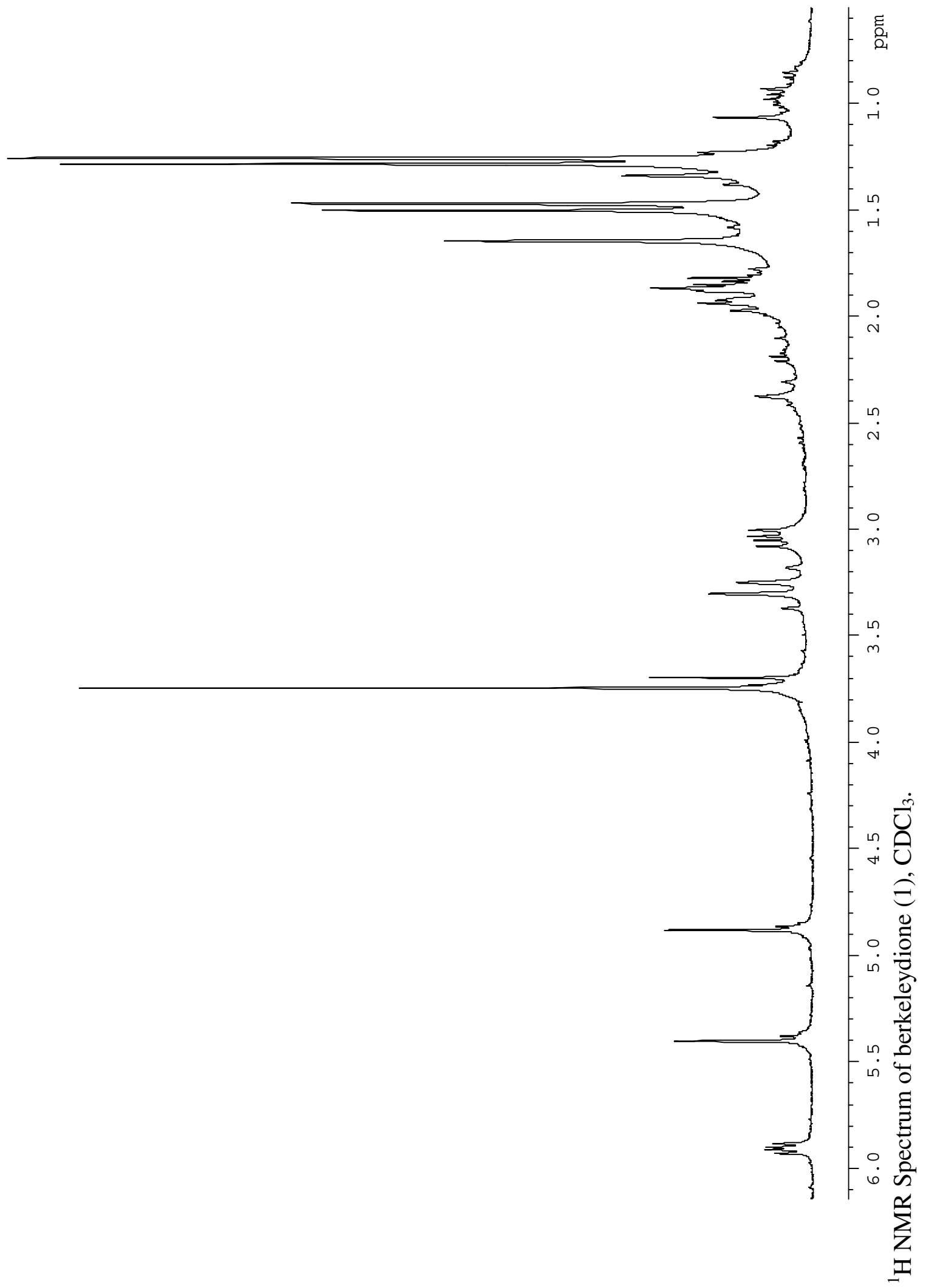



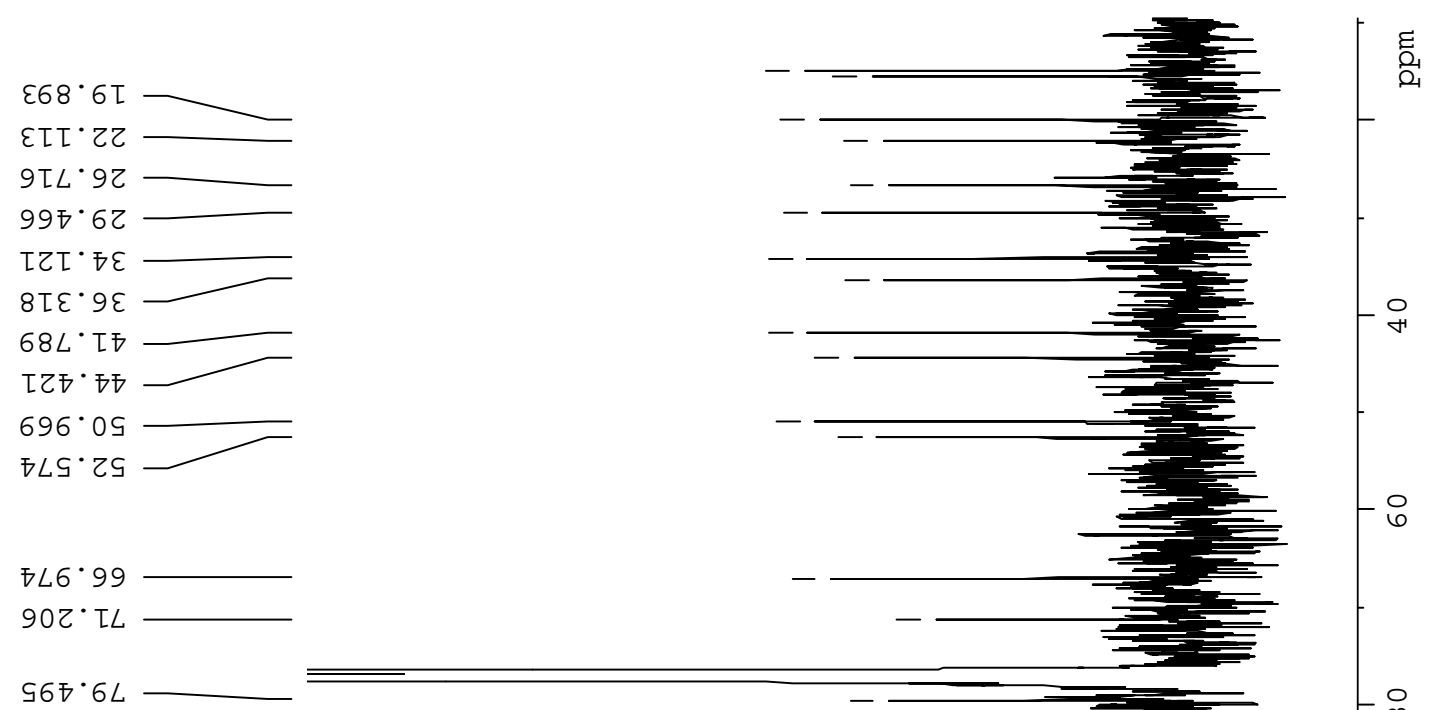

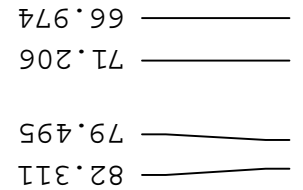

$\varepsilon \subseteq \tau \cdot \varepsilon \tau \tau$

$L \varepsilon I \cdot 9 Z I$

$6 L S^{*} 6 Z I$

५8โ ऽع

$\varepsilon\llcorner 8 \cdot 6 \varepsilon L$

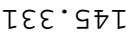

S20.69I -

ฤ88.69 I

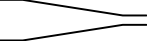

LOL'TOZ

OLE'LOZ

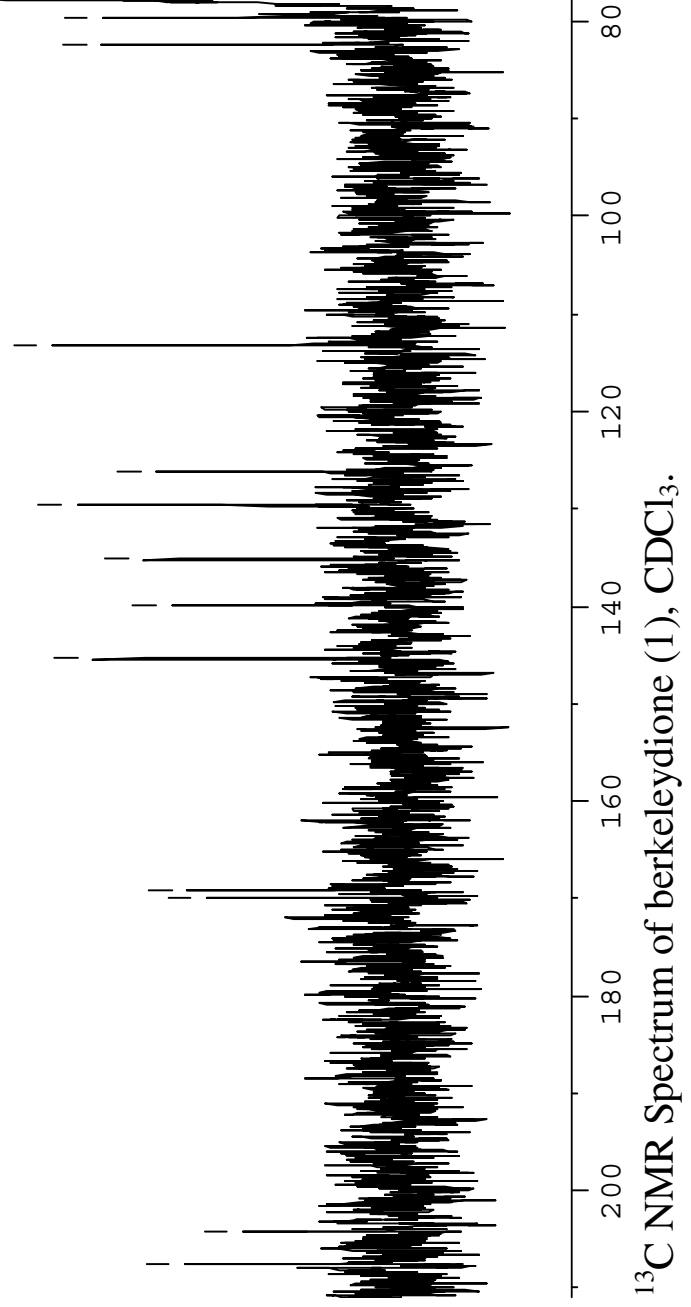




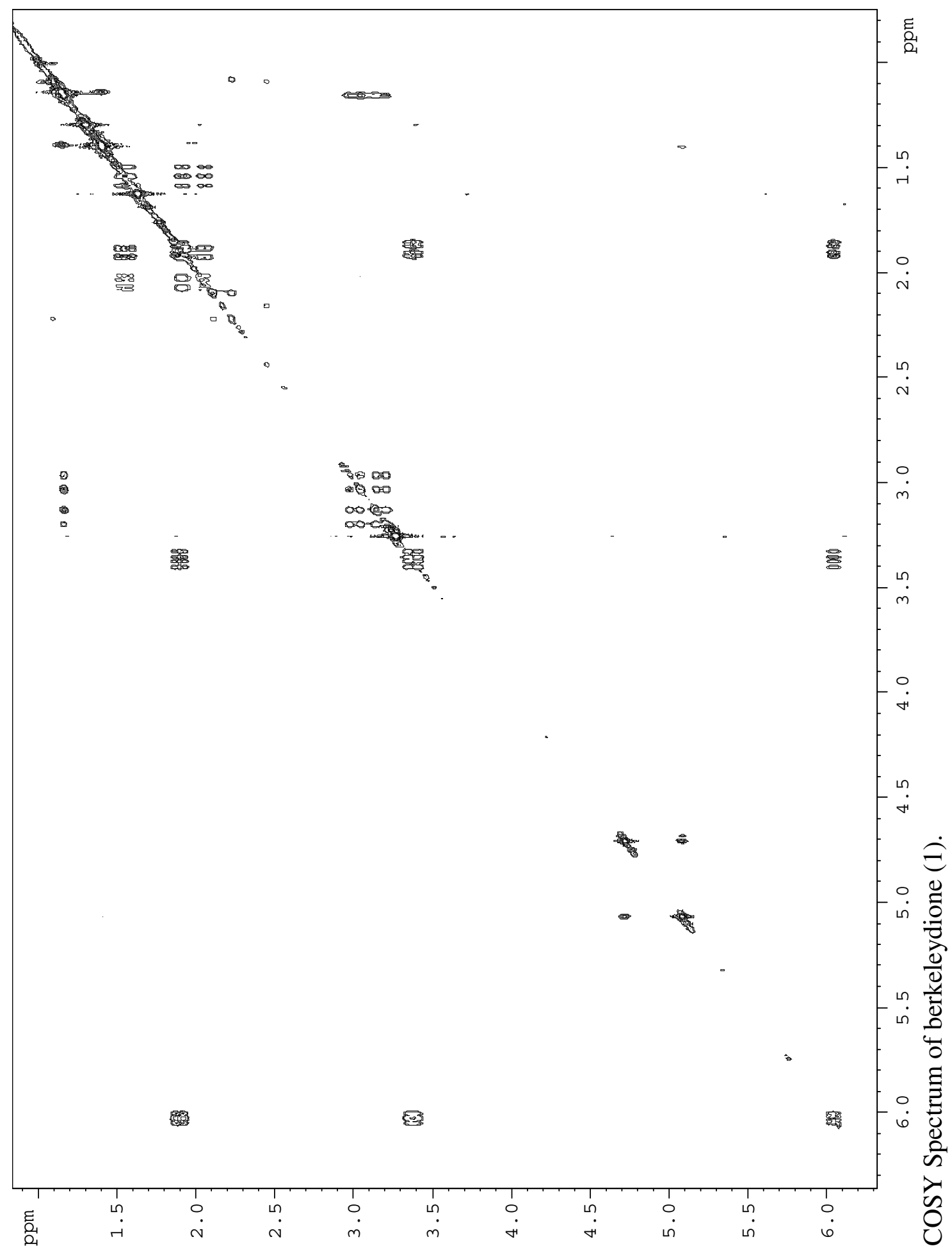




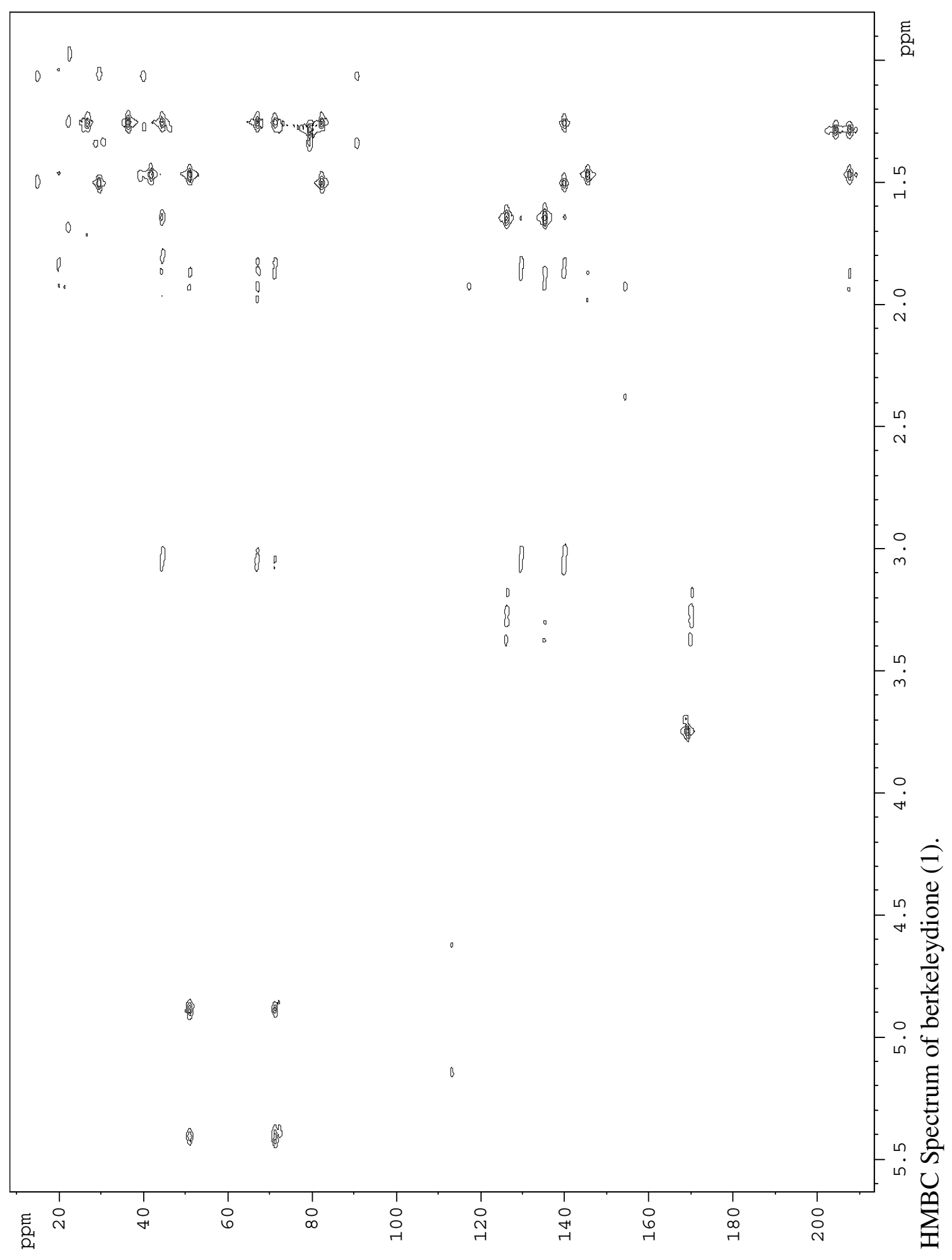




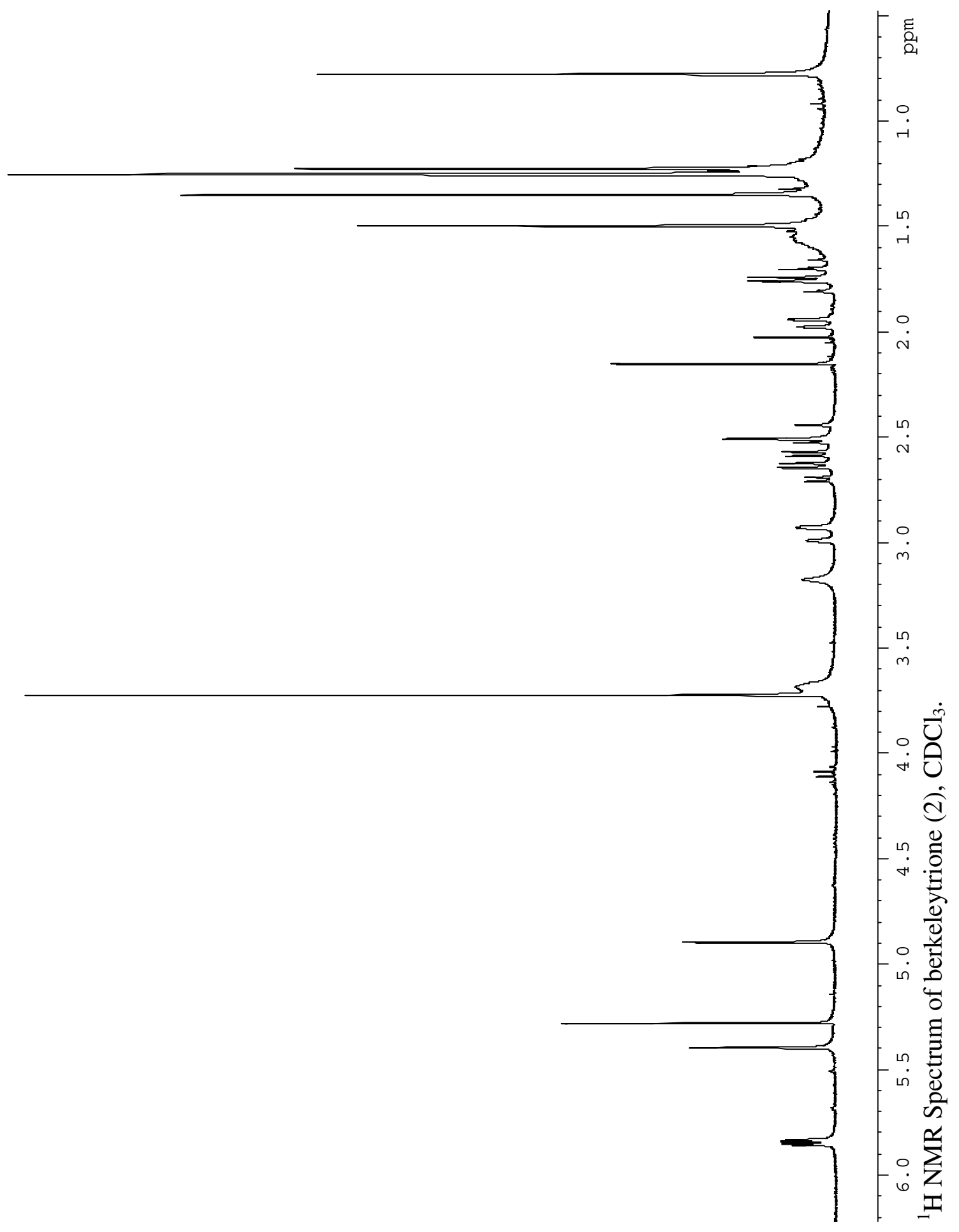



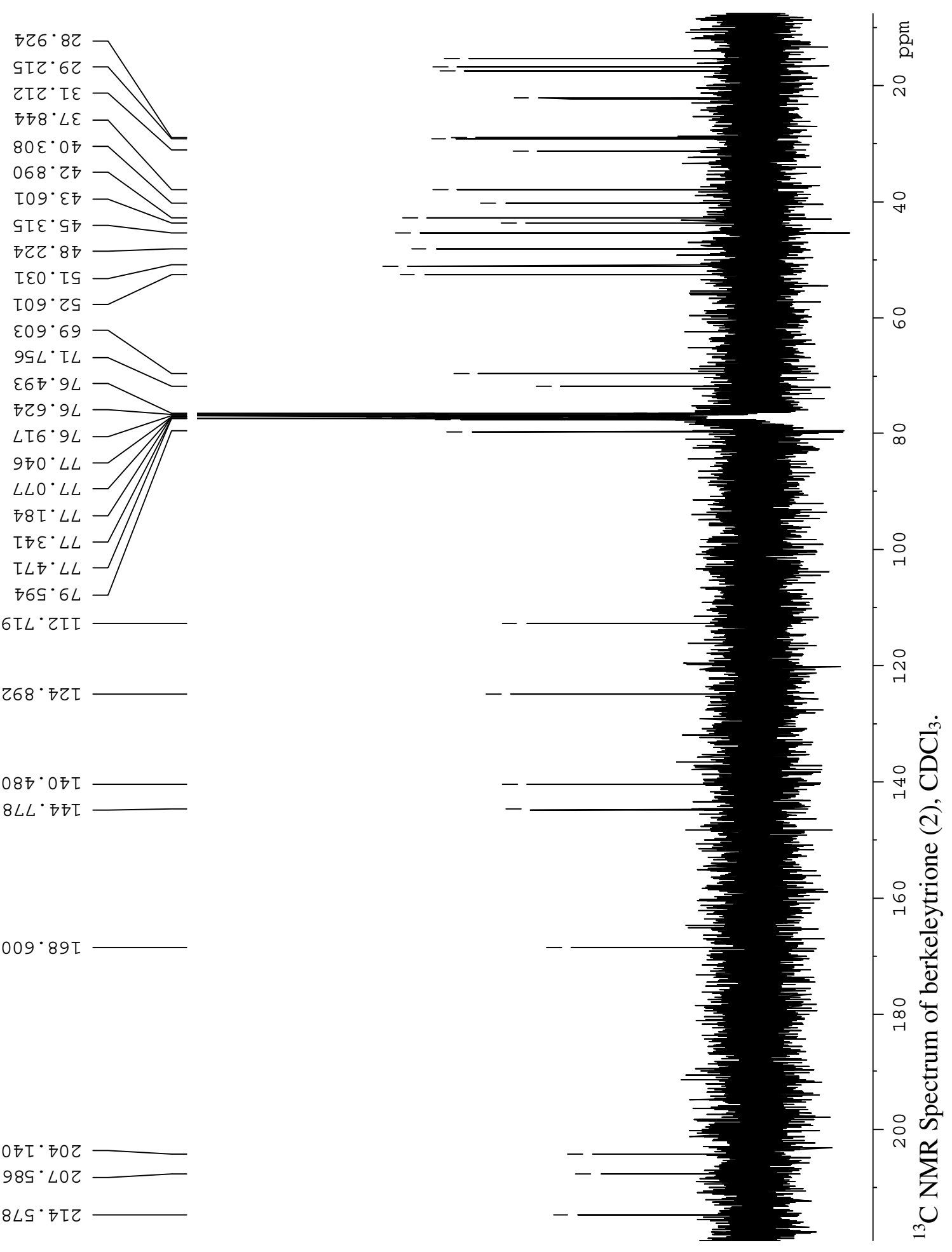

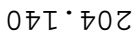

985 'LOZ

8LS'

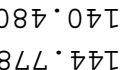

$009 \cdot 89 I$ 


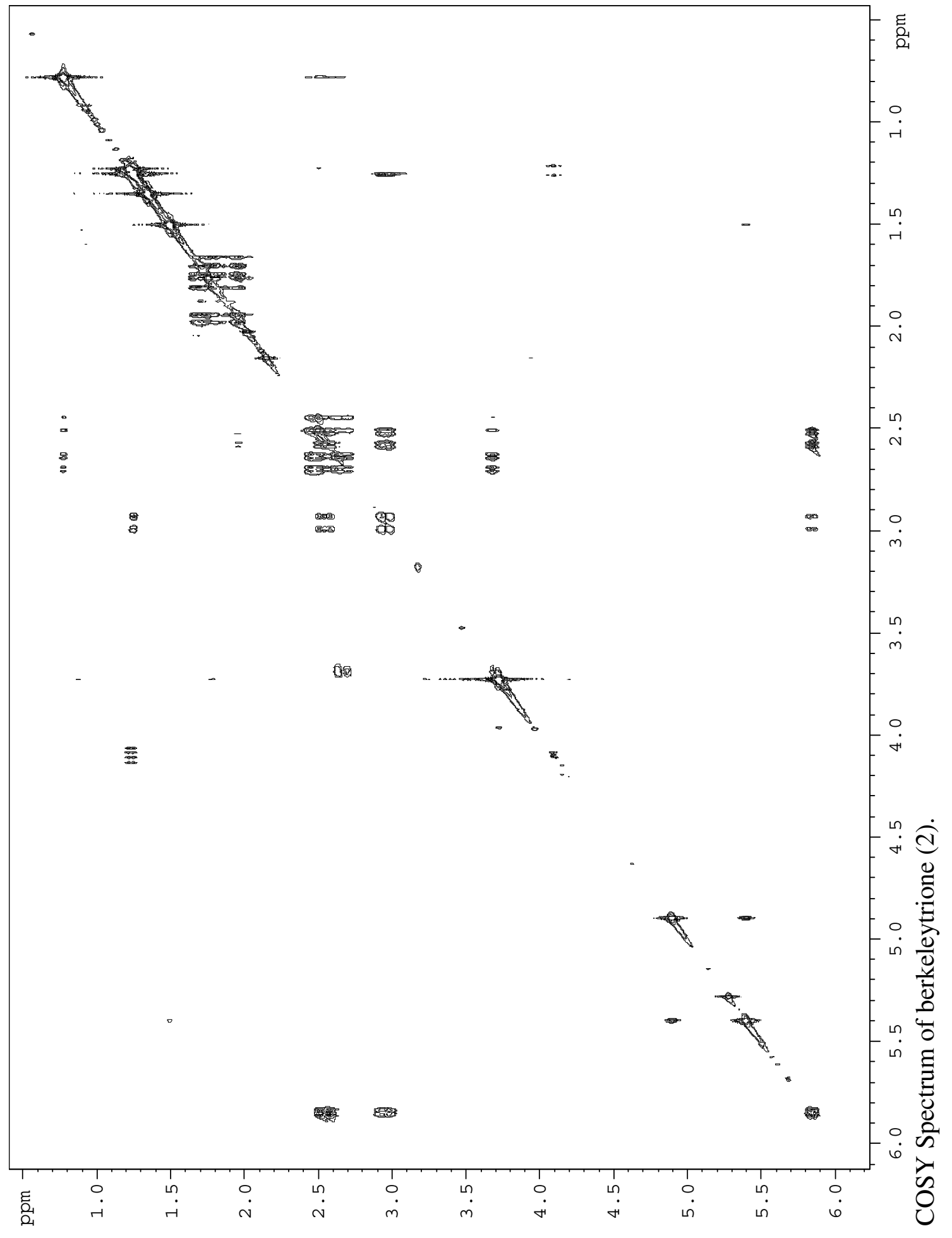




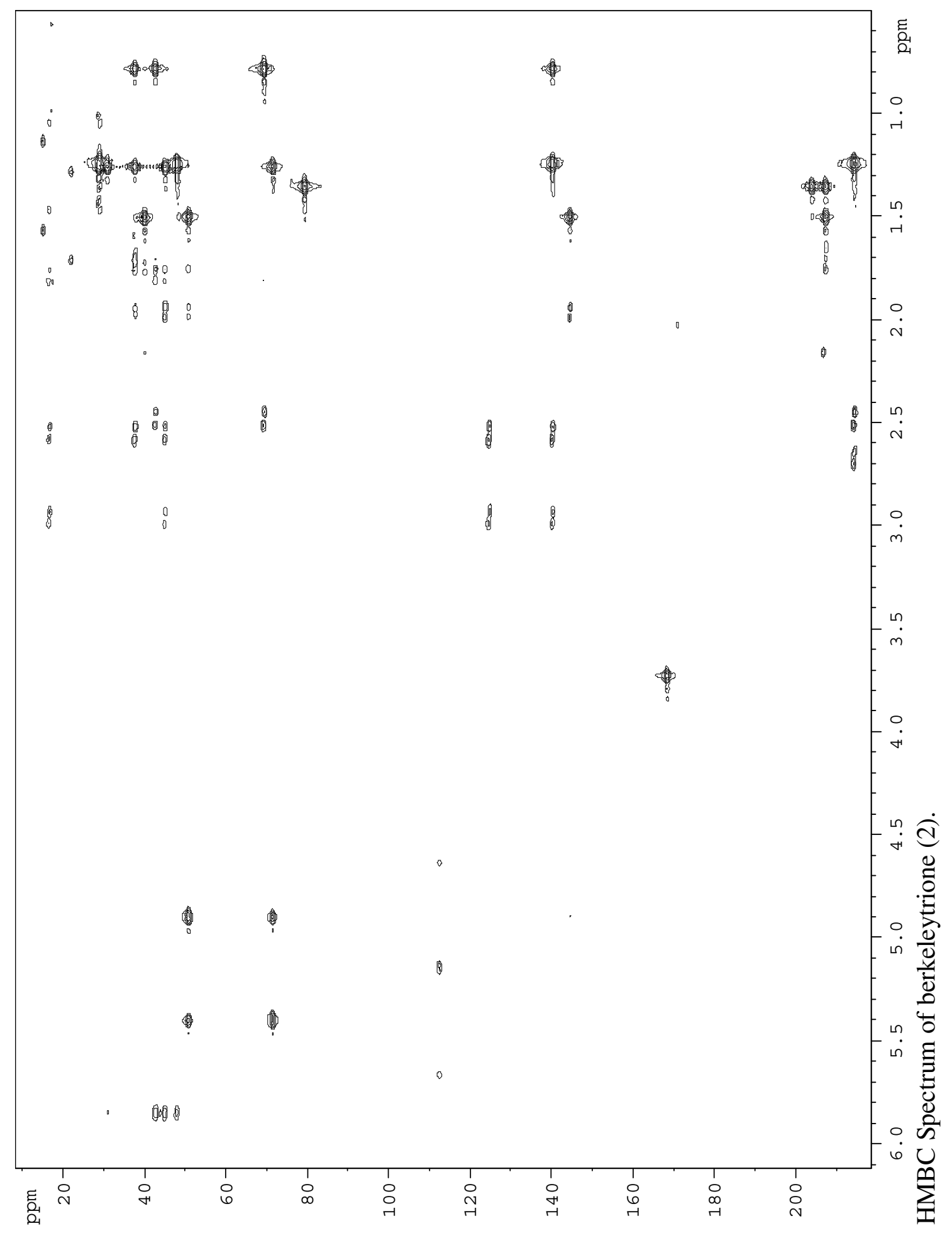




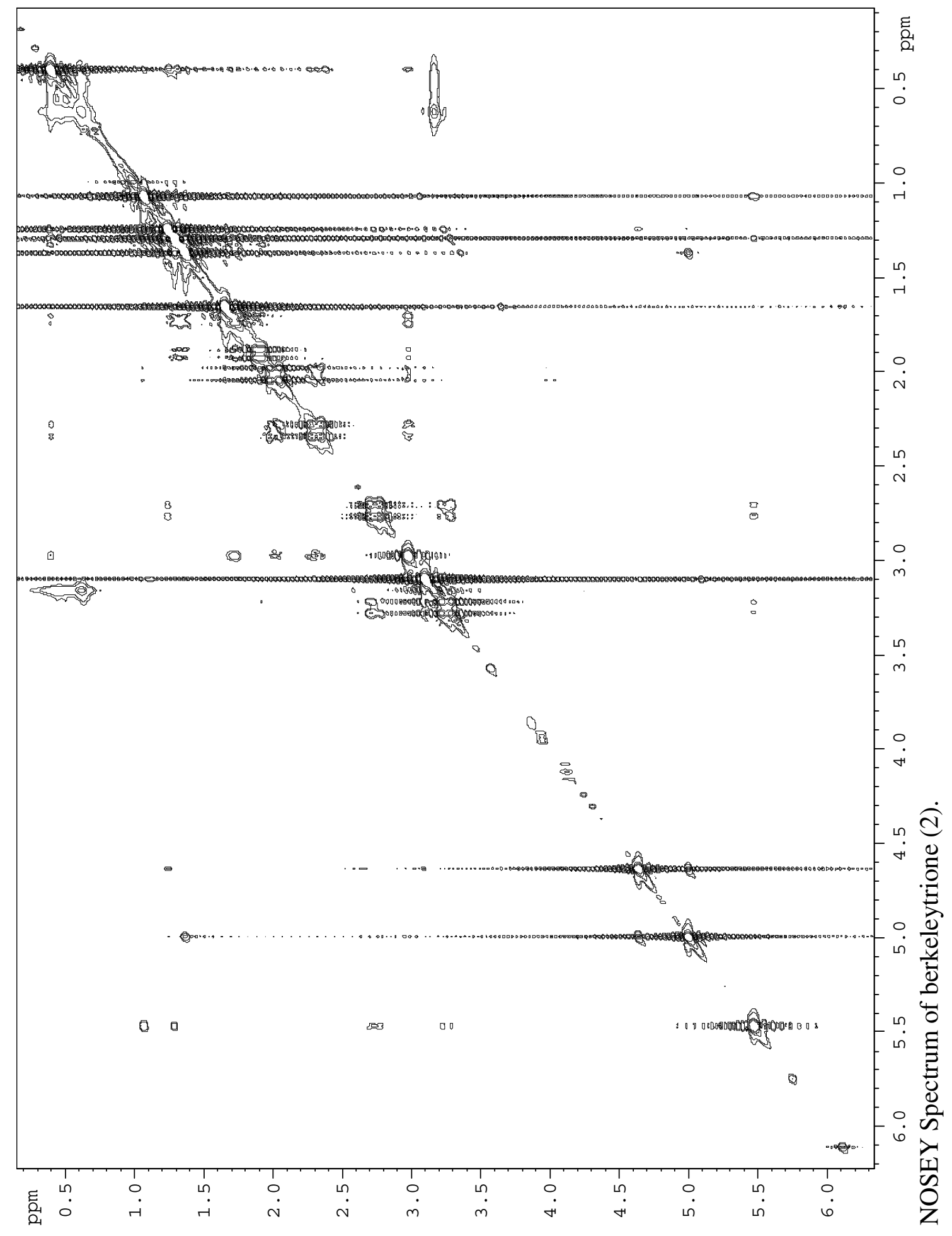

